\title{
POR ENTREPOLÍTICAS, PRÁXIS E LETRAMENTOS CRÍTICOS: UM OLHAR SOBRE A DOCÊNCIA DE LÍNGUA INGLESA NO PIBID
}

\author{
Silvana Fernandes de Andrade* \\ Diógenes Cândido de Lima**
}

\begin{abstract}
Resumo: Traçamos filiações teóricas e metodológicas ao estado da arte do ensino e aprendizagem de língua inglesa (LI), enfocando a prática docente. Nosso objetivo geral é analisar como os letramentos críticos (LCs)contribuem para a práxis do docente de línguas no tocante à formação de cidadãos críticos.Propomos uma alternativa à prática docente no PIBID de LI da Universidade Estadual do Sudoeste da Bahia (UESB), segundo os letramentos críticos, mais condizente com as demandas contemporâneas. Embasado na pesquisa etnográfica, este trabalho insere-se no paradigma qualitativo de investigação. São apresentadas reflexões (análise de questionário) oriundas dos instrumentos utilizados em diferentes momentos da pesquisa e que apontam para a necessidade de melhor discutir e abordar novos caminhos ao ensino de línguas.
\end{abstract}

Palavras-chave: Formação Cidadã. Letramentos Críticos. Políticas Linguísticas. Práxis.

\begin{abstract}
We have traced both theoretical and methodological affiliations to the state-of-the-art of English language teaching and learning, by emphasizing the teaching practice. Our overall aim is to analyze how critical literacies contribute to the language teacher praxis, towards a critical citizen education. We propose an alternative for English language teaching, within the PIBID at Bahia Southwestern State University (UESB), according to critical literacies, which is more compatible with contemporary demands. Based on ethnography research, this study integrates the qualitative research method. Reflections (questionnaire analysis) stem from methodological instruments used in different moments of research, and point to the need to better discuss and approach new directions to language teaching.
\end{abstract}

Keywords: Citizen education. Critical Literacies. Linguistic Policies. Praxis.

\section{Introdução}

Norbert Elias (1998), em Sobre o Tempo, relata a história de um grupo de pessoas que subia cada vez mais alto no interior de uma torre elevada e desconhecida. Os que faziam parte da primeira geração atingiram um patamar que, pela segunda geração, foi vencido. Pela terceira, também superado. No correr do tempo, seus descendentes alcançaram um andar ainda mais alto, fazendo a escada desmoronar. Esses últimos desconheciam como os seus antepassados habitaram os andares inferiores e passaram a residir no centésimo piso, ignorando como um dia outros seres humanos teriam ido até ali. "Chegavam até a acreditar que as representações que forjavam para si a partir da perspectiva de seu andar eram compartilhadas pela totalidade dos homens" (ELIAS, 1998, p.108).

As torres, sejam elas de marfim ou de Babel, são elementos recorrentes no arcabouço literário das Letras para explicar o papel reservado ao homem nestes tempos de complexidade, ou, como escreveria Bauman (2000), na presente e conflituosa Modernidade Líquida.

É possível dizer que os homens na torre de Elias aludem ao indivíduo pós-moderno, produto das constantes mudanças e fluxos culturais, sócio-políticos e econômicos e que, por

\footnotetext{
* Mestranda do Programa de pós-graduação em Letras: Cultura, Educação e Linguagens (PPGCEL) da Universidade Estadual do Sudoeste da Bahia (UESB). Endereço eletrônico: silvanandrades@ gmail.com

** Pós-doutor em estudos de Linguística Aplicada pela Florida International University, doutor em Educação com concentração em estudos da Linguagem pela Southern Illinois University at Carbondale, professor pleno de Língua Inglesa e Linguística Aplicada da Universidade Estadual do Sudoeste da Bahia (UESB). Endereço eletrônico: dlima49@gmail.com
} 
meio da velocidade no espaço cibernético, bem como as novas tecnologias de informação e de comunicação, vem sendo atravessado em todos os âmbitos da vida pública e nas esferas individuais. Tal como as gerações no interior da torre de Elias (1998), o homem contemporâneo vê-se preso aos paradigmas de uma modernidade líquida, ou seja, às acelerações constantes que o fazem escolher o seu modo de ser e estar no mundo e compreender o outro em função dos discursos dominantes.

É bem verdade que a ideia de movimento e mudança é condição sinequa non para que a humanidade se transforme. Contudo, conforme sinaliza Santos, M. (1994), a respeito da atualidade, "trata-se de uma nova fase da história humana", deveras divergente de todas as "ondas" e "levas" que a antecederam.

Nota-se em Santos (2000) uma preocupação no que concerne ao controle institucional de domínio ideológico, manobras de um jogo político de grandes dimensões em que os discursos vão instituindo proposições quase que inquestionáveis sobre seus particípies: indivíduos e Estado, dispondo ou não de meios materiais para participar desse processo, assistem, em sua maioria, ao centro do sistema impor uma globalização ainda de cima para baixo aos demais países. Segundo o autor, é patente a reflexão sobre as proporções, desdobramentos e reflexos dessas ações sobre a vida dos sujeitos:

Para a maior parte da humanidade, o processo de globalização acaba tendo, direta ou indiretamente, influência sobre todos os aspectos da existência: a vida econômica, a vida cultural, as relações interpessoais e a própria subjetividade. (...) Os indivíduos não são igualmente atingidos por esse fenômeno, cuja difusão encontra obstáculos na diversidade das pessoas e na diversidade dos lugares. Na realidade, a globalização agrava (essa) heterogeneidade. (SANTOS, 2000, p. 02).

Por essa razão, o homem contemporâneo, tal qual os demais da torre mencionada, se sente compelido a apressar-se para fazer parte do grupo dos notáveis, que dão as cartas e influem no rumo da história, muitas das vezes sem refletir criticamente sobre custos e consequências dessa empreitada. O que evita é fazer coro junto aos invisíveis de nossos tempos, sujeitos cujas trajetórias aludem ao atraso.

\section{Políticas linguísticas, práxis e ensino de língua inglesa}

A Língua Inglesa, enquanto insigne tradutora dos processos globais, é considerada como a "chave para o sucesso". Conforme salienta Rajagopalan (2004, p. 12):

A demanda pelo aprendizado de inglês cresceu em proporções geométricas, como fica evidenciado pelo estupendo número de escolas de idioma que se proliferaram por todo o país, quase tão rapidamente quanto as filiais do MC Donald's. O conhecimento da língua é simplesmente pressuposto por corporações multinacionais quando anunciam vagas de trabalho. E o público em geral resignou-se há bastante tempo ao fato de que o inglês oferece um passaporte para o sucesso profissional.

O 'público em geral' a que se refere o autor (2004), compreende, é claro, professores e alunos nas mais diversas instituições espalhadas pelo mundo. Segundo Bohn (2013), estes educandos e educadores têm aderido às universalizações e normalizações do mercado de trabalho, que, por seu turno, é produtor de abismos entre os sujeitos contemporâneos, como salienta De Sousa Santos (2010). 
Dados coletados qualitativa e quantitativamente em 2014 pelo Instituto de Pesquisa Data Popular, demonstrados no documento intitulado Demandas de Aprendizagem de Inglês no Brasil para o British Council, não só tratam da perspectiva mercadológica de inglês no país, como também as necessidades, hábitos e práticas mais comuns entre os brasileiros na relação com a Língua Inglesa. Dessa pesquisa foi possível depreender que a maior faixa etária de falantes de Língua Inglesa encontra-se entre 18 e 24 anos (10,3\%), caindo pela metade $(5,2 \%)$ para os que estão entre 25 e 34 anos, segunda maior faixa etária apresentada. Entre a população que declara ter conhecimento de Inglês, 47\% diz possuir nível "básico", 32\% nível "intermediário", $16 \%$ nível "avançado" e 5\% declara não saber mensurar o que sabe. Entre os professores, $81 \%$ dos professores de Inglês são mulheres. 52\% são graduados há mais de uma década e $45 \%$ do montante total não faz capacitação pedagógica, sendo que a maioria dos que já fizeram formação continuada tiraram dinheiro de seus próprios bolsos para fazê-lo. 55\% dos educadores relataram que um dos maiores empecilhos que enfrentam é a "falta de oportunidade para conversar em inglês" e a "dificuldade com a língua falada" (22\%). 33\% dos professores possuem certificado de proficiência no idioma.

No tocante a questões de mercado, $57 \%$ dos que estão fazendo curso de Inglês acredita que o salário melhora através da aquisição do conhecimento da língua, enquanto que $51 \%$ dos que pretendem fazer Inglês julga também que terá melhores salários por meio do conhecimento de inglês que pretendem adquirir.

Afirma o autor (2013, p. 88), respaldado em Mafffesoli (2005, p. 88), que a corrida em busca de um espaço na universidade economicista e a ênfase na preparação pura e estrita para essa conquista têm gerado graves consequências, a que resume dessa forma: "Quando o valor da vida dá lugar ao valor da utilidade, assistimos ao triunfo de uma degenerescência que, sob o manto do moralismo é, de fato, uma negação ou a denegação em seu sentido pleno" (BOHN, 2013, p. 88).

Abordando temas caros à filosofia, Vázquez (1968) tentou explicar as nuances entre prática e práxis, o que, em nossa leitura, pode ser interpretado à luz do campo educacional na relação com a lógica de mercado, que o circunda. Prático "é o ato ou objeto que produz uma utilidade material, uma vantagem, um benefício (...) o prático é produtivo, e produtivo, por sua vez, do prisma dessa produção, é o que produz um novo valor ou mais-valia" (VAZQUEZ, 1968, p. 12).

Se nos reportarmos ao campo educacional, a educação de línguas que queremos ter se assemelha muito mais à práxis, não há dúvidas. A atividade professoral não pode ser concebida com o caráter prático-utilitário tão somente e que se pode depreender do significado de "prático" na linguagem corrente. Limitada à atividade material, a docência fica reduzida a um conceito econômico. Fora do caráter transformacional, contudo, não há práxis, propriamente dita, mas mera atividade docente ou prática.

$\mathrm{Na}$ tentativa de ressignificar o ensino de LI em razão dos novos processos mundiais, documentos e diretrizes vêm sendo modificados, de modo a dialogar com a complexidade do momento em voga. São as chamadas Políticas Linguísticas (doravante PLs) para o ensino de línguas.

Segundo Rajagopalan (2013), as PLs, enquanto campo de estudos institucionalizado e legitimado, datam de meio século aproximadamente, muito embora a questão política sempre tenha acompanhado a linguagem na história da humanidade.

As PLs possuem papel fundamental na proposição de ações no campo educacional e voltaram ao centro das discussões depois de terem estado às margens do esquecimento por um período considerável. Contudo, elas ainda causam grandes controvérsias, sobretudo no que diz respeito ao que significam os termos e suas peculiaridades enquanto campo de saber.

Conforme salienta o autor (2013), a PL não se trata de uma ciência exata, regida por lógica, regras e leis infalíveis. Por essa razão, não tem relação com a Linguística, ciência do 
século XIX e que teria atingido a efervescência com a publicação do clássico livro Curso de Linguística Geral de Ferdinand Saussure em 1916. As PLs referem-se à língua, bem como à política, podendo ser pensadas como política "relativa à(s) língua(s)" (RAJAGOPALAN, 2013, p. 20), ou ainda:

(...) a arte de conduzir reflexões em torno de línguas específicas, com o intuito de conduzir ações concretas de interesse público relativo à(s) língua(s) que importam para o povo de uma nação, um estado ou ainda, instâncias transnacionais maiores. (RAJAGOPALAN, 2013, p. 21).

Embora incompreendidas ou rejeitadas por uma gama de pesquisadores que almejam cientificidade, as PLs encontram-se hoje em constante processo de reinvenção e aprimoramento, conforme mencionado acima. Contudo, sempre buscaram espaço no cenário do ensino e aprendizagem de LI através de diretrizes e legislações em curso e em diferentes momentos da história, nem sempre gerando decisões producentes e acertadas.

\section{Os letramentos críticos na relação com a docência de língua inglesa: um enquadramento teórico}

Segundo Monte Mór (2013), a modernidade tem exigido da sociedade uma gama de habilidades para a vivência na presença do fenômeno da globalização e da crescente expansão da tecnologia digital. Nessa seara, o desenvolvimento crítico é uma dessas habilidades, um desses anseios presentes nas legislações e reiterado pelos letramentos críticos, haja vista a preocupação desse campo de estudos, em especial, com a formação de cidadãos críticos.

Em se tratando do ensino e aprendizagem de línguas, para muito além do conhecimento das quatro habilidades, o letramento crítico enfoca o contexto ideológico e cultural do qual os sujeitos fazem parte como necessidades que precisam integrar as agendas de ensino e aprendizagem de línguas, uma vez que não é mais possível conceber o professor de línguas com um ser acrítico, apolítico, "como se as aulas de línguas estrangeiras não fossem corresponsáveis pelo desenvolvimento da cidadania crítica tal como as demais disciplinas curriculares" (DUBOC, 2015, p. 15).

Advogando em prol dessa episteme, Wielewicki (2007. p. 53) pontua:

(...) eu acredito que o principal objetivo de uma educação crítica deve ser o de ajudar os estudantes a reconhecer o poder que eles já possuem para transformar conhecimento em possibilidades significativas de modo a modificar suas realidades, contribuindo, assim, para a construção de uma sociedade melhor.

Segundo Gregory e Cahill (2009) em Constructing Critical Literacies: self-reflexive ways for curriculum and pedagogy, o letramento crítico envolve "leitura de mundo", de modo que então possamos juntos, na condição de crianças, jovens e adultos, compartilhar essas visões, entender as estruturas de poder que nos permeiam e qual a nossa participação nelas. Requer diálogo, conforme pontuam, e nos provê com insumos para a reflexão e capacidade de ação.

Da leitura que empreendem de Comber (2007), Shannon (1995) e Luke e Freebody (1997), as autoras (2009) chegam a um panorama sobre o tema. Para o primeiro (2007), "o letramento crítico é o uso da língua de maneiras poderosas que orientam o agir sobre o mundo, melhoria da vida na escola e questionamento de privilégios e injustiças". Para Shannon (1995), "o letramento crítico é o letramento que traz consigo a liberdade de explorar 
e agir sobre o nosso passado, presente e futuro" enquanto que para os últimos (1997), diz respeito ao "ensino e aprendizagem de pontos de vista, normas de ações sociais e consequências" (GREGORY; CAHILL, 2009, p. 07).

Mas há quem se recuse a tratar da politização e engajamento enquanto horizontes a serem vislumbrados na confecção de novas agendas para a educação. As razões para tanto são várias, podendo estar calcadas no medo do desconhecido, das represálias que a luta contra o dominante possam ocasionar, para citar alguns exemplos.

Rejeitar a tensão que os letramentos críticos desejam instaurar é, na concepção de Gregory e Cahill (2009), um ato reducionista e que corrobora para a manutenção do estado de cegueira em nós e em nossos estudantes acerca das injustiças que nos rodeiam. Significa, sobretudo, deixar que o currículo escolar seja confeccionado à nossa revelia, bem como manipular a construção da subjetividade pelos nossos alunos.

De acordo com as autoras, quando escolhemos não nos engajar,

(...) nós nos tornamos complacentes em perpetuar a ideologia dominante, empregando uma concepção bancária de educação que nos permite, através de nossa instrução, conferir o conhecimento que temos para os ditos menos conhecedores, negando a bagagem de conhecimento que nossos alunos trazem consigo (...) Estas são as salas de aula as quais mantêm e perpetuam o dogma que o texto (isto é, os materiais impressos) dão sentido, ao contrário de conter um sentido que pode ser construído e negociado pelo leitor (...)" (GREGORY; CAHILL, 2009, p. 08).

Enunciando a partir do mesmo lócus, Mattos e Valério (2010) caracterizam a então episteme enquanto perspectiva de trabalho indicada pelas OCEM (2006), já que nesse campo de estudos, a língua é encarada como um "recurso dinâmico para criação de significados" pelos sujeitos, e a língua materna/ estrangeira, mais especificamente, como palco de transformação de si mesmo e da sociedade. Trazem, em seu texto, questões pontuais e muito caras aos letramentos, a exemplo da autonomia do aprendiz, lugar da norma e utilização de material autêntico, para citar algumas temáticas.

Já nos primeiros desenhos de seu texto, as autoras (2010) celebram o fato de que os letramentos críticos conferem mais protagonismo aos aprendizes, se comparados ao ensino tradicional. Porque não engajado, o ensino tradicional, em suas palavras, "está a serviço da perpetuação das relações de poder já existentes, promovendo a conformação ao privar o indivíduo de oportunidades para questionamentos". Complementam: "O LC tem objetivo inverso ao da educação tradicional, pois promove o empoderamento do aprendiz, que é levado a apropriar-se do seu próprio processo educacional" (MATTOS e VALÉRIO, 2010, p. 141).

$\mathrm{Na}$ leitura que depreendemos das autoras, essa liberdade e protagonismo se manifestam através de uma sala de aula acolhedora, humana, no sentido freireano do termo e que se sabe espaço social e negocia saberes, ao invés de ditar "regras de conduta que delegam ao professor o monopólio do saber e do controle das regras interacionais, as quais incluem o comando do sistema de troca de turnos (...)" (MATTOS e VALÉRIO, 2010, p. 140).

As convicções supramencionadas são igualmente compartilhadas por Jordão (2013). A autora postula que, ao contrário da abordagem comunicativa e da pedagogia crítica, que centram o conhecimento no professor como exímio conhecedor da língua, seja de sua estrutura ou ideologia, no letramento crítico o que há são muitos os sentidos e verdades possibilitados pelas ideologias percebidas e aprendidas por alunos e professores conjuntamente. "Nesse sentido, o sujeito não assimila passivamente conteúdos, opiniões e saberes, mas os "articula, em um trabalho ativo, em relação à sua trajetória, seus conhecimentos prévios e seus interesses" (MAGNANI, 2011, p. 4 apud JORDÃO, 2013, p. 77). 
No tocante ao ensino de normas e variedades, assuntos os quais não se furtam de discutir à luz desse campo do saber, Mattos e Valério (2010) se posicionam favoravelmente ao ensino de um sistema linguístico-cultural homogêneo sempre em face de muitas outras possibilidades, tendo em vista a heterogeneidade e diversidade de culturas e povos. O modelo da norma não deve ser negligenciado, mas "identificado, compreendido como elemento transformador, o que pode ser feito por meio da observação e análise desse sistema em comparação a outros sistemas linguísticos e sócio-culturais". A partir desse olhar crítico e cuidadoso é que "esse sistema, antes visto como homogêneo e único estaria a serviço da educação para a cidadania (...)", o que concordamos em absoluto.

Em Takaki (2012, p. 976, grifo nosso), as mesmas noções quanto ao não tangenciamento dos aspectos linguísticos são compartilhadas. O letramento crítico é tratado no plural e, enquanto letramentos críticos "requerem um professor que crie espaço para diálogos em que a voz do aluno e sua criatividade sejam valorizadas tanto quanto $o$ desenvolvimento linguístico". Isso nos permite afirmar que se trata de uma atuação responsável, já que a competência linguística não é descartada, pois que se encontra entrelaçada à formação dos educandos.

Em relação à escolha e o uso de material didático em sala, Mattos e Valério (2010) levantam uma questão da maior importância: o papel do livro didático em face dos materiais autênticos. Da leitura que empreendem de Nunan (1999, p. 27), a autenticidade se caracteriza como "amostras de língua oral ou escrita que não tenham sido escritos especificamente com o propósito de se ensinar uma língua” (MATTOS; VALÉRIO, 2010, p. 144), o que é da maior relevância em se tratando de letramentos críticos.

Em nosso entendimento, a autenticidade se vale de materiais adaptados para uma proposta de ensino que não se deseja mecânica ou artificial, já que, em contrapartida, as invencionices de um texto elaborado para cumprir tão somente o papel de ensinar um determinado aspecto não poderia ser capaz de revelar o que a língua é, em essência: uma prática social. O parágrafo a seguir, embora extenso, elucida melhor essas concepções:

A autenticidade para o LC é ainda mais premente, impondo-se como fator indispensável para sua realização (...) A compreensão da língua como prática social estaria, pois, vinculada a sua gênese em um determinado contexto, uma vez que somente esse contexto poderia viabilizar a compreensão das relações de poder por ela retratadas, mantidas e / ou construídas. Textos, para o LC, devem permitir ao aluno compreender a ideologia e as regras socioculturais, discursivas e linguísticas de diferentes substratos sociais em diversas situações. Para ilustrar essa diversidade, podemos citar as diferentes regras de conduta que norteiam o comportamento linguístico de um indivíduo em família, em seu trabalho, e, ainda, entre amigos no clube, por exemplo. Como se poderia compreender, então, a utilização de dados inventados para informar o aluno a respeito da realização discursiva de diferentes segmentos sociais? Como poderia um autor criar uma interação entre companheiros de 'pelada', por exemplo, sem impor sobre ela seus próprios padrões linguísticos, culturais e ideológicos e suas próprias perspectivas de interpretação? (MATTOS; VALÉRIO, 2010, p. 145).

Caracterizados como "linha de pesquisa independente" ou muito mais como "atitude filosófica", os letramentos críticos ocupam, igualmente, lugar de destaque no trabalho de Duboc (2015). Leitora de Woolridge (2001), Duboc (2015, p. 97) concorda com ela ao postular que "o letramento crítico é uma orientação ao letramento: não algo separado do letramento em geral (...) o letramento crítico não é uma técnica ou conjunto de estratégias, mas, sim, uma pedagogia por trás de toda uma abordagem ou prática de sala de aula". É também levada a concordar com Lankshear e Knobel (1997), uma vez que "o letramento 
crítico surge como requisito para formação de uma "cidadania ativa" para além do civismo nacionalista, calcado agora na diversidade dos novos tempos" (DUBOC, 2015, p. 99).

Tendo emergido nos anos 60 por influência dos estudos da pedagogia crítica de Freire, os letramentos críticos, em suas palavras, prezam pelo

(...) desenvolvimento de habilidades que capacitem o cidadão a ler criticamente as práticas sociais e institucionais e a perceber a construção social e situada do texto e da linguagem por meio da compreensão das suas fontes, propósitos, interesses e condições de produção. Tal proposta busca, portanto, expandir o projeto moderno que institui a produção de sentidos como se a relação sujeito-objeto fosse neutra, natural, fixa, estável, inocente no intuito de desnaturalizar o natural, questionar, problematizar, duvidar, suspeitar (DUBOC, 2015, p. 93).

Em nossa leitura, o fato da autora se valer dos letramentos críticos enquanto campo que possa capacitar o cidadão, nas suas palavras, nos faz pensar no quanto há uma estreita relação entre esse domínio e a promoção da cidadania.

Concordamos com os autores supramencionados, especialmente com Duboc (2015, p. 15) para quem o exercício da problematização é questão da maior relevância na atividade cotidiana do docente de línguas, uma vez que circula o que ela nomeia de uma "(...) visão estereotipada e discriminatória do professor de línguas como ser acrítico e apolítico, como se as aulas de língua estrangeira não fossem corresponsáveis pelo desenvolvimento da cidadania crítica tal como as demais disciplinas curriculares". Para Duboc (2015), é preciso, pois, entender, em primeiro lugar e com propriedade, a que conceito de crítica estamos nós, docentes, nos reportando. Para tanto, pontua:

Estudos da sociologia e da teoria crítica vêm problematizar a concepção moderna de crítico ao final do século XX ao entender o crítico não apenas como discernimento do real, daquilo que supostamente encontrar-se-ia pronto ou acabado, mas como um exercício dialético na relação desse real com as tensões e conflitos de nosso entorno. (DUBOC, 2015, p. 94).

Empreendendo esforços na mesma direção, Monte Mor (2013) celebra o interesse cada vez maior por pesquisas no âmbito dos letramentos críticos através das legislações que têm se interessado em formar cidadãos críticos. Em tempo, cita em seu trabalho nomes de pesquisadores com os quais dialoga acerca do tema crítica, a exemplo de Vattimo (1990) e Gikandi (2005), Leavis (1969), Barthes (1999), Carraher (1999), Faraco e Tezza (2001), entre outros. Contudo, Ricouer (1997) parece ser o teórico com quem a autora estabelece laços teóricos mais estreitos.

A posição que o autor (1997) nos revela sobre crítica está fundamentada na palavra crise: "Para ele, a apreensão da relação crise-crítica tem relação direta com o processo de ruptura de um padrão tradicional ou do andamento regular de um determinado raciocínio" (MONTE MOR, 2013, p. 39). Portanto, é preciso lançar mão da crise, de uma hermenêutica da suspeita, como sugere a pesquisadora, com o intuito de desestabilizar nossos sentidos e nas nossas visões de mundo.

Nessa seara, muitos autores têm tentado remar longe dos domínios do modo "apropriado" de fazer letramento crítico, o que é claramente justificável, já que não se trata de uma ciência exata, não se pode falar em metodologia ou prescrição, os sentidos não estão prontos em um determinado texto, bem como não existe uma receita, por assim dizer, que nos ensine a prepará-lo em nosso meio. Contudo, há na literatura, certos pressupostos que devem ser compartilhados, haja vista a sua função de ambientar educadores para vir a fomentar focos de crise e desestabilização em suas salas de aula e instaurar possibilidades de agência. Duboc 
(2015) traz alguns questionamentos que podem ser feitos em prol de um trabalho crítico e que aqui recuperamos dada a importância dos mesmos:

O que estou fazendo aqui lendo este texto? De onde o texto fala? Qual realidade é apresentada/ construída neste texto? Da perspectiva de quem é construída? Como o texto conceitua X? Como X se constitui no texto? O que o texto deixa de dizer? O que o texto desconsidera ou considera irrelevante? $\mathrm{O}$ que coloca no centro? O que deixa às margens? Que outras possíveis versões são excluídas? Essas versões respondem aos interesses de quem? De que formas (elementos linguísticos-textuais) o texto constrói essa realidade? Como o texto posiciona o leitor? (DUBOC, 2015, p. 101).

\section{0 contexto e a natureza da pesquisa}

Antes mesmo de revelar e discutir os dados e resultados obtidos no trabalho de campo, julgamos necessário fazer algumas considerações sobre nossa pesquisa.

Esse estudo insere-se no campo das pesquisas de ordem qualitativa, haja vista a complexidade e dinamicidade dos fenômenos humanos e sociais, o estudo do fenômeno em seu "acontecer natural" (ANDRÉ, 2012).

Em linhas gerais, por ter recebido influências teóricas da fenomenologia, a pesquisa qualitativa destaca os aspectos subjetivos do comportamento humano, a importância de adentrar o universo dos sujeitos pesquisados e as suas experiências cotidianas para compreender o sentido que atribuem às suas realidades, as suas vivências. De maneira muito semelhante opera a etnografia, uma de suas influências e ramificações:

A preocupação da etnografia é com os significados que têm as ações e os eventos para as pessoas ou grupos estudados. Alguns desses significados são expressos pela linguagem, outros são transmitidos indiretamente por meio das ações (...) A etnografia é a tentativa de descrição da cultura. Geertz (1973) utiliza o termo "descrição densa", que ele tomou emprestado do filósofo Gilbert Ryle, para designar o que pretende a etnografia (ANDRÉ, 2012, p. 20).

Desenvolvida pelos antropólogos e educadores, a etnografia chega às salas de aula na tentativa de descrição da cultura enquanto práticas, hábitos, valores, crenças, linguagens e significados de um conjunto social. Para tanto, os pesquisadores devem fazer uso das técnicas que são tradicionalmente associadas à etnografia, a saber: a observação participante, a entrevista intensiva e a análise dos documentos.

A observação é chamada de participante porque parte do princípio de que o pesquisador tem sempre um grau de interação com a situação estudada, afetando-a e sendo por ela afetado. As entrevistas têm a finalidade de aprofundar as questões e esclarecer os problemas observados. Os documentos são usados no sentido de contextualizar o fenômeno, explicitar suas vinculações mais profundas e completar as informações coletadas através de outras fontes. (ANDRÉ, 2012, p. 28).

Com isso em mente, e munidos de autorização, adentramos o grupo de sujeitos do PIBID de Língua Inglesa da Universidade Estadual do Sudoeste da Bahia (UESB). É válido mencionar que o PIBID é o nome pelo qual nos reportamos ao Programa Institucional de 
Bolsas de Iniciação à Docência e que o estudo que apresentamos é apenas um dos eixos que integra a nossa pesquisa de mestrado em vias de conclusão.

Segundo informações fornecidas pelo Portal do Ministério da Educação, o programa PIBID visa integrar instâncias diversas, tais como as secretarias estaduais e municipais de educação e universidades públicas em prol da melhoria do ensino nas escolas públicas. Para tanto, os alunos bolsistas selecionados das licenciaturas, junto aos seus coordenadores (professores da universidade e responsáveis pelo programa nesses espaços) e professores supervisores - sendo estes últimos os professores da escola pública onde os bolsistas vão estagiar - são convidados, ao partilhar do mesmo espaço de discussões e a convergir o olhar sobre o objeto que interessa a todos: o exercício da docência e seus desafios.

Atualmente, o PIBIB de Língua Inglesa promove duas rodas de discussão semanais: às quartas-feiras, das $8 \mathrm{~h} 30$ às $10 \mathrm{~h} 30$ no interior da escola parceira/universidade, visando o exercício da docência de Língua Inglesa na perspectiva do Ensino Médio, sob coordenação de uma docente, em específico (doravante LIEMVC); às quartas-feiras, das 8h30 às $10 \mathrm{~h} 30$ no interior da universidade/escola parceira, visando o exercício da docência de Língua Inglesa na perspectiva do Ensino Fundamental, sob a coordenação de outra docente, também integrante do Departamento de Letras da universidade supramencionada (LIEFVC).

O grupo de LIEMVC tem 11 graduandos em Letras, uma professora coordenadora (PC) e uma professora supervisora (PS).

Os alunos participantes (doravante B1, B2, B3, B4, B5, B6, B7, B8, B9, B10, B11) são, em maioria, jovens do sexo feminino, oriundas de outras localidades do Estado e que se encontram em diversos momentos do curso de Letras Modernas na UESB. Ressalta-se que i) B11 é professor de uma escola de línguas de grande porte da cidade de Vitória da Conquista e não esteve presente no primeiro momento da pesquisa pelo acúmulo de tarefas na tentativa de conciliar trabalho e conclusão de curso; ii) B10 esteve ausente em todos os momentos em que a pesquisa ocorreu por ter tido o seu vínculo encerrado, pois foi recentemente aprovada em seleção de mestrado na UESB; iii) a professora supervisora (PS) esteve ausente na maioria dos encontros por motivo de doença. Em suma, da entrevista coletamos o relato de oito bolsistas presentes.

A princípio, lançamos mão de um questionário aberto que continha perguntas segmentadas em três blocos, dado o teor das mesmas: dados pessoais (Bloco 1), profissionais (Bloco 2) e conceitos (Bloco 3); promovemos manhãs de formação com uso de textos-base sobre novas epistemes, letramentos críticos e crítica; propiciamos a elaboração de atividades e coletamos os últimos dados através de entrevista.

A pesquisa foi realizada entre os meses de março e abril de 2016 e documentada através de gravações de áudio e vídeo e anotações de campo.

Revelamos e discutimos aqui apenas o questionário, dando enfoque especial à docência e analisando os demais dados à luz dos letramentos críticos e demais temáticas mencionadas.

\section{1 A docência de língua inglesa em foco e os letramentos críticos em contexto}

\subsubsection{Bloco 1}

No que tange à geração e análise de dados, o Bloco 1, relativo às informações pessoais dos sujeitos investigados (bolsistas e professor supervisor), apontou para a uma maior representatividade das mulheres no grupo PIBID LIEMVC, que reivindicam para si a fatia de um pouco mais de $60 \%$ no número total de participantes. No tocante ao gênero, a participação um pouco mais expressiva das mulheres em relação aos homens no que diz 
respeito à ocupação desse lugar de docência (PIBID LIEMVC) reitera os dados da pesquisa encomendada pelo British Council em 2014, anteriormente citados neste trabalho.

Os bolsistas, em sua maioria, são oriundos de outras cidades do Estado, estão na faixa etária dos 21 aos 34 anos de idade e encontram-se nos mais variados estágios do curso de Letras Modernas da UESB (III, IV, VI e VIII semestres). Coincidentemente ou não, os sujeitos entrevistados nesta pesquisa estão entre as duas maiores faixas de falantes de inglês no país, como também demonstrado através dos dados registrados pelo documento do British Council, a saber, 18 a 24 anos e 25 a 34 anos de idade.

\subsubsection{Bloco 2}

Quando perguntados acerca de sua experiência docente (Bloco 2), mais especificamente sobre os seus objetivos ao planejar as aulas, 12,5\% (B8) forneceu uma resposta vaga, que consistia em "colocar os alunos para trabalhar e desenvolver o máximo o aprendizado da língua inglesa". 37,5\% dos bolsistas (B1; B4; B5) mencionaram priorizar alguma forma de conteúdo, a exemplo de "aspectos culturais", "pronúncia", "aquisição de vocabulário", "tradução", enquanto 50\% (B2; B3; B6; B7) demonstraram preocupação maior em gerenciar os aspectos emocionais em sala de aula. Foi recorrente nos registros escritos desse último grupo a utilização de vocábulos e expressões do tipo "engajamento", "despertar o interesse", "aula cativante, aceitável", "atividades interessantes", "conhecimento para a vida".

Destacam-se dois posicionamentos antagônicos: enquanto B5 parece apresentar um conceito de língua mais estrito ("trabalhar com os alunos atividades que envolvam o exercício da pronúncia, aquisição de vocabulário, tradução e aprofundamento de maneira geral, os conhecimentos acerca da língua inglesa"), B6 registra um posicionamento mais emancipatório, progressista e que nos interessa, pois que não visa à aprendizagem de línguas na relação prática-utilitária: obter nota e aprovação quando registra: "objetivo de que os alunos aprendam a língua inglesa (na medida do possível) de forma que esse conhecimento adquirido se leve para a vida e não "decorar" momentaneamente para alcançar uma boa nota e assim uma aprovação". B4, por sua vez, cita, dentre outras questões, que parte de um "planejamento unilateral", o que nos chama atenção, pois se pressupõe que o sujeito em questão compreende que o exercício de planejar parte do professor para o aluno e é solitário.

Quando perguntados sobre como descrevem o exercício da docência, 75\% (B1; B2; B3; B4; B5; B6) dos bolsistas recorreram a adjetivos/expressões positivas para descrevê-lo, tais como "MARAVILHOSO!", "importante", "troca", "incentivo à reflexão", "gratificante". Apenas $25 \%$ (B7; B8) deles fizeram uso de expressões positivas com ressalvas, a exemplo de "trabalhoso, mas gratificante" ou "desafiador, mas nos remete à responsabilidade de formar cidadãos (...)".

Nota-se mais uma vez em B6 uma valorização da reflexão e o tangenciamento da ideia prática-utilitária de língua quando diz: "O exercício docente para mim é uma espécie de incentivo à reflexão, uma janela que se abre para o conhecimento, auxiliando e questionando, a fim de exercitar a interação e induzir ao pensamento de forma não mecânica". B7 segue uma linha de pensamento muito parecida quando afirma que "O exercício da docência, além de desafiador, nos remete à responsabilidade de formar pessoas, cidadãos. Exercer o papel de professor é despertar o pensamento crítico e desenvolver habilidades conscientes no ser humano". Nota-se o uso da palavra cidadãos e pensamento crítico, o que significa muito para nós. Todavia, a construção do pensamento final com a utilização da partícula "no" em "(...) desenvolver habilidades críticas no ser humano" denuncia uma perspectiva de crítica que a bolsista tem em mente e que se faz de A para B e não de A com B como na pedagogia crítica de Freire. Mais uma vez destacamos o posicionamento de B4 que parece estar querendo chamar a nossa atenção para algo ao complementar que, no exercício de troca que a atividade 
docente significa para ele, "alunos e professores aprendem um com o outro, embora isso não exima o educador de se posicionar como figura principal do levantamento de discussões", o que nos remete a Duboc (2015) quando postula que o professor não está mais para a figura de um negociador de sentidos em sala.

Vale lembrar que as pesquisadoras Mattos e Valério (2010) também empreendem esforços nessa mesma direção, acreditando que deva haver mais protagonismo por parte dos aprendizes, se comparados ao ensino tradicional. Porque não engajado, o ensino tradicional, em suas palavras, "está a serviço da perpetuação das relações de poder já existentes, promovendo a conformação ao privar o indivíduo de oportunidades para questionamentos". Complementam: "O LC tem objetivo inverso ao da educação tradicional, pois promove o empoderamento do aprendiz, que é levado a apropriar-se do seu próprio processo educacional” (MATTOS; VALÉRIO, 2010, p. 141).

$\mathrm{Na}$ leitura que depreendemos das autoras, essa liberdade e protagonismo se manifestam através de uma sala de aula acolhedora, humana, no sentido freireano do termo e que se sabe espaço social e negocia saberes, ao invés de ditar "regras de conduta que delegam ao professor o monopólio do saber e do controle das regras interacionais, as quais incluem o comando do sistema de troca de turnos (...)" (MATTOS; VALÉRIO, 2010, p. 140).

As convicções supramencionadas são igualmente compartilhadas por Jordão (2013). A autora postula que, ao contrário da abordagem comunicativa e da pedagogia crítica, que centram o conhecimento no professor como exímio conhecedor da língua, seja de sua estrutura ou ideologia, no letramento crítico o que há são muitos os sentidos e verdades possibilitados pelas ideologias percebidas e aprendidas por alunos e professores conjuntamente. "Nesse sentido, o sujeito não assimila passivamente conteúdos, opiniões e saberes, mas os "articula, em um trabalho ativo, em relação à sua trajetória, seus conhecimentos prévios e seus interesses" (MAGNANI, 2011, p. 4 apud JORDÃO, 2013, p. 77).

O professor, portanto, não precisa centralizar o planejamento em suas mãos, fazendo dele uma atividade "unilateral", nas palavras de B4. Ser negociador de sentidos junto aos alunos não o exime da função de professor, preocupação de B4.

B5, por sua vez, que apresentou uma concepção bastante estrita de língua nas questões anteriores, afirma que a docência é "algo de extrema e fundamental importância para a formação do caráter, da natureza e do intelecto humano (...) só através dela conseguiremos construir um país melhor para nós e para as futuras gerações", o que nos revela o quanto ele parece ciente do compromisso que a profissão requer.

Questionados se os conteúdos trabalhados em sala de aula possibilitam uma relação direta com o contexto do aluno e de que forma, ficamos surpresos com as mais variadas respostas. Através de um questionamento dessa natureza, desejávamos saber em que medidas aqueles professores em pré-serviço compreendiam a sua função de letrar criticamente o aluno, já que é premente que o professor desenvolva "habilidades que capacitem o cidadão a ler criticamente as práticas sociais e institucionais e a perceber a construção social e situada do texto e da linguagem" (DUBOC, 2015, p. 93), pois que o texto, os gêneros, a linguagem não são inocentes e suas fontes, propósitos e condições de produção precisam ser contextualizados, trabalhados em conjunto, o que para nós é ponto crucial da docência. Ademais, como salienta Duboc (2015), ainda que o trabalho docente se rotule como crítico, se desenvolver estratégias objetivas e distantes da realidade do aluno, terá outra concepção de criticidade, próxima da Antiguidade Clássica, que tem por objetivo o Cogito e o esclarecimento de verdades de um texto - o que não interessa aos letramentos críticos.

Como a questão dividiu opiniões, assim categorizamos as respostas: $25 \%$ (B3; B4) não respondeu; $12,5 \%$ (B7) mostrou descrença ao registrar "em muitos casos não"; $25 \%$ (B1; B6) revelaram que "nem sempre" ou "depende" e 37,5\% (B2, B5 e B8) afirmaram que 
"sim", sendo que B8 apenas registrou "Sim" em sua resposta, sem as explicações que a questão requeria. O bolsista que registrou "em muitos casos não", acredita que isso deve ao nosso modelo atual de ensino, pois que "limita a relação dos conteúdos transmitidos em sala com a realidade do aluno" uma vez que são "ensinados de maneira fria, imparcial e distante" e que nossa função, enquanto educadores, é a de "transpor essas barreiras que nos são impostas", mas não cita de que maneira devemos proceder. Nota-se que apenas B6 fornece uma resposta sobre como fazê-lo, na sua opinião: "trabalhar com música, séries, filmes... coisas que sejam do cotidiano do aluno". Quando da nossa análise, as noções de contexto e de como atuar nas brechas do conteúdo na relação com o contexto do aluno precisam ser revisitadas, já que não há consenso sobre a possibilidade de fazê-lo, sobretudo um registro claro dos sujeitos sobre de que maneira o docente pode fazê-lo.

Indagados sobre o lugar do livro didático na sua vivência de docência, observamos respostas divergentes: 12,5\% (B1) declarou que não sabe utilizar, mas o considera "legal"; $12,5 \%$ (B2) disse que não utiliza, "mas é um suporte" $12,5 \%$ (B4) o caracterizou como "não tão importante"; 12,5\% (B8) acredita que "não deve ser utilizado"; 50\% (B3; B5; B6; B8) declaram que é "bom", um "aliado" e que não deve, respectivamente, "assumir o papel de agente de ensino", "prender e limitar" o trabalho do docente ou "ser a única ferramenta em sala de aula", enquanto que 25\% (B2; B7) acredita que o livro didático deve condicionar o fazer docente, pois que "é um lugar onde o aluno poderá entender (...), de fato, o que é apresentado pelo professor em sala de aula" e "exerce o papel apenas de direcionar e organizar os conteúdos e determina a ordem em que estes são ensinados".

Do montante geral, nota-se que 6 dentre os 8 sujeitos entrevistados, o que representa $75 \%$ do grupo de bolsistas que respondeu ao questionário 1, utilizam de ressalva para posicionar-se, recorrendo à conjunção "mas" para externar seus pontos de vista. Os vocábulos que usam para caracterizar o livro didático, em linhas gerais, são: "recurso", "suporte", "lugar", "ferramenta", "aliado", "companheiro", "instrumento", muito embora os termos "material" e "ferramenta" tenham sido mais citados. Os dados gerados nos levam a crer que embora qualificado como "bom" na maioria das respostas - pois que "é um dos poucos recursos que o aluno e professor dispõe" (B1; B4), o livro didático é indesejado. Compreender o papel que ele desempenha no cotidiano da sala de aula precisa ser pauta de discussões mais amplas. Contudo, imaginamos que essa escolha talvez encontre filiação nos pressupostos de Mattos e Valério (2010), quando as autoras mencionam a escolha e o uso de material didático em sala em face dos materiais autênticos. Valendo-nos da visão holística preconizada pelos estudos etnográficos, percebemos, em conversa informal entre os sujeitos e fora do áudio, que os bolsistas mencionaram produzir muitos materiais autênticos junto ao professor coordenador (PC) e ao professor supervisor (PS).

Reiteramos o pensamento de Mattos e Valério (2010). Conforme já citado anteriormente, da leitura que empreendem de Nunan (1999, p. 27), as pesquisadoras caracterizam a autenticidade como "amostras de língua oral ou escrita que não tenham sido escritos especificamente com o propósito de se ensinar uma língua" (MATTOS; VALÉRIO, 2010, p. 144), o que é da maior relevância em se tratando de letramentos críticos.

Em nosso entendimento - como já mencionado antes - a autenticidade se vale de materiais adaptados para uma proposta de ensino que não se deseja mecânica ou artificial, já que, em contrapartida, as invencionices de um texto elaborado para cumprir tão somente o papel de ensinar um determinado aspecto não poderia ser capaz de revelar o que a língua é, em essência: uma prática social.

Interpelados sobre o que se deve priorizar na/para a elaboração das aulas, 25\% (B2; B7) do grupo mencionou que sua preocupação maior é com a satisfação e aceitação da turma; $25 \%$ (B2; B3) citou perfil/ nível/ faixa etária; 37,50\% (B2; B4; B5) disse priorizar gramática, gêneros textuais, vocabulário, pronúncia e conteúdo; 37,50\% (B3; B6; B7) 
mencionou contexto, "familiarização dos alunos com o conteúdo" e "gêneros próximos da vida dos alunos". O bolsista B8 (12,5\%) apresentou uma resposta que não conseguimos mapear, uma vez que registrou apenas "o aprendizado do aluno", aprendizado esse que não podemos traçar filiações e conceitos. Chama-nos a atenção, contudo, a maneira pela qual B2 caracteriza o diálogo entre professor e aluno: “(...) o conteúdo que será exposto, porque deve haver algum aprendizado por parte do aluno (ainda que de forma indireta, através de uma simples conversa)". Em nossa leitura, o diálogo, pensado como "conversa" é algo "simples", talvez menos importante porque é, no dizer do sujeito, uma "forma indireta" de levar o aprendizado. Ao revés disso, podemos também pensar que, muito embora o diálogo seja algo "simples", representa um espaço potencial de aprendizado que não deve ser tangenciado.

Pode-se concluir que B5 mantém as crenças sobre suas concepções de língua já mencionadas, ao passo que a maioria dos sujeitos estão divididos em dois grupos distintos: entre a priorização de conteúdo ou priorização de contexto. É válido recuperar o que postula Duboc (2015, p. 15), quando do docente que ensina conteúdos meramente, sem um trabalho crítico, nas "brechas": ele contribui para uma visão estereotipada de professor de língua estrangeira "como ser acrítico, apolítico, como se as aulas de línguas estrangeiras não fossem corresponsáveis pelo desenvolvimento da cidadania como as demais disciplinas curriculares".

Sobre o processo de planejamento e como o descrevem, muitas foram as denominações empregadas: "momento fundamental de repensar", "complexo", "essencial para uma boa aula", "produtivo", animador-frustrante", importante", repetição "dos mesmos vícios de nossos professores", "momento de organizar" e "organização". 25\% (B5; B7) mencionam que é o momento de selecionar os conteúdos para serem trabalhados. B6, por seu turno, diz-se preocupada em repetir "os mesmos vícios" de nossos professores, pois que seguem o "tradicionalismo". É nesse processo que ela então se pergunta como fazer diferente, "como me planejar para levar algo diferente para a sala de aula, algo que talvez fizesse falta em meu tempo de aluna".

O sujeito B6 nos chama atenção para um dos temas da filosofia da práxis: a aspiração à práxis. B6 desconfia que há uma maneira de fazer diferente que se opõe ao tradicionalismo. $\mathrm{O}$ que B6 aspira é a práxis, mas provavelmente não sabe. Isso se deve à sua cotidianidade condicionada sócio historicamente (VAZQUEZ, 1968), o que interpretamos como a sua condição de universitário na busca por conhecimento para refletir sobre a sua docência e gradativamente "melhorá-la", por assim dizer:

Não podemos dizer, de modo algum, que ele viva num mundo absolutamente a-teórico (...) Sua própria cotidianidade está condicionada histórica e socialmente, e o mesmo pode-se dizer da visão que tem da própria atividade prática (...) por conseguinte, sua atitude diante da práxis já implica numa consciência do fato prático (...) Sua consciência da práxis está carregada ou penetrada de ideias que estão no ambiente, que nele flutuam e as quais, como seus miasmas, ele aspira (...) Portanto, a consciência comum da práxis não está descarregada por completo de certa bagagem teórica, ainda que nesta bagagem as teorias se encontrem degradadas (VAZQUEZ, 1968, p. 09).

Acerca dos recursos/estratégias disponíveis utilizados na interação face a face com o aluno, 37,5\% (B1; B2; B6) mencionou o diálogo; 50\% (B2; B5; B4;B7) destacou lousa/aparelho de áudio/ material didático/ sala de vídeo/ quadro/ piloto/ recursos gráficos/ colagens; $12,5 \%$ (B3) destacou o contexto, ao mencionar que tenta "relacionar o que é ensinado às suas vivências", 12,5\% (B8) disse "tudo o que puder ser utilizado", o que não conseguimos caracterizar, uma vez que a sua resposta se resume assim. B4 é o único ao 
mencionar que faz uso apenas de piloto e voz. O contexto precisa ser melhor definido já que é premissa dos letramentos críticos.

Em relação a como os bolsistas avaliam o seu conhecimento da língua inglesa, 37,5\% (B1; B2; B3) avalia negativamente o que sabe da Língua Inglesa, recorrendo aos vocábulos e expressões "precário", "poderia ser bem melhor", "preciso, a cada dia melhorar"; 12,5\% (B4) acredita que seu conhecimento é avançado; $25 \%$ (B5; B6) disse que era intermediário, mas que está em transição devido ao curso de Letras e apontam, respectivamente, que adquiriu "certas noções de gramática que me ajudaram no aprimoramento sobre a língua inglesa" e que "minha percepção e meu vocabulário teve um avanço considerável" ; 12,5\% (B7) julga seu conhecimento como "intermediário e suficiente" e 12,5\% conceitua como "básico" o seu entendimento da língua inglesa. Em linhas gerais, desse montante, apenas 25\% (B4; B7) verbaliza estar satisfeito com conhecimento que possui. Os dados estabelecem uma relação com a pesquisa encomendada pela British Council, uma vez que a maioria dos que disseram falar inglês - não necessariamente professores de LI - julga-se insatisfeita com o nível de proficiência que possui.

Quando provocados a mensurar a proporção em que falam inglês em cada aula, os sujeitos registraram respostas diversas. Lançaram mão de situações específicas, adjetivos de intensidade, bem como porcentagem, escalas e níveis para demonstrar, em tese, como se dá o uso oral da língua. Resgatamos o depoimento de cada um deles: "pouquíssimo, apenas quando vou ler (...) ou quando os alunos perguntam"; "mais ou menos metade da aula, pois os alunos não possuem conhecimento suficiente da língua para que sejam ministradas em inglês"; "05\%", "falo sempre que a turma perde o foco"; "de 0 a 10 (...) nível 4"; "apenas palavras que serão trabalhadas e chamo atenção para a pronúncia"; "numa proporção que me permite uma comunicação que esteja no nível dos alunos" e "na proporção das atividades propostas". Nenhum dos sujeitos registrou falar mais da metade do tempo ou em tempo integral.

\subsubsection{Bloco 3}

Desse momento em diante, trataremos dos achados no Bloco 3, cujos questionamentos direcionados aos sujeitos foram de ordem conceitual, que visou compreender os sentidos que os entrevistados atribuíam a alguns termos relevantes de nossa pesquisa.

Perguntados se já ouviram falar de política linguística para o ensino de língua inglesa no Brasil e, em caso afirmativo, que se posicionassem, 75\% (B1; B3; B5; B7; B8) dos sujeitos disseram nunca ter ouvido falar; enquanto que $25 \%$ (B2; B4) conceituou o campo, respectivamente, dessa maneira: "Não com essa mesma definição, porém há uma seção nos PCNs (Parâmetros Curriculares Nacionais) que aborda essa temática (este eu tenho conhecimento) e "Trata-se de ações que poderiam ser adotadas para melhorar o aprendizado de uma língua estrangeira", o que nos convida a refletir. Nota-se que B2 cita um exemplo de política linguística implícita, ainda que diga que não tem segurança em conceituar o termo, enquanto que B4 acredita que as políticas, indiscriminadamente, contribuem para melhorar o aprendizado da língua.

Indagados sobre se já ouviram falar sobre letramentos críticos, 25\% (B1; B3) disse que sim, mas não sabe conceituar, todavia B3 arriscou um posicionamento: "mas acredito que esteja relacionado à capacidade dos sujeitos se expressarem criticamente sobre os diversos acontecimentos, temáticas que o circulam"; $25 \%(\mathrm{~B} 2 ; \mathrm{B} 4)$ verbalizou que sim e o conceituou, cada um à sua maneira desse modo: "sim e concordo plenamente com ele. Conheci o letramento através de uma professora e ultimamente venho estudando sobre isso. Ele nada mais é do que capacitar os alunos para que estes consigam discutir sobre temas 
atuais sem nenhuma dificuldade" enquanto que B4 declarou que acredita ser "a capacidade de reagir/ opinar/ entender textos". A maioria dos bolsistas, 50\% (B5; B6; B7; B8), revelou que não conhece o que chamaram de "texto", "tema", "termo". "Capacitar os alunos" também nos remete à concepção bancária de Freire da qual já nos reportamos anteriormente.

Sobre o que se deve ensinar hoje de inglês e se isso já foi diferente antes, nos parece importante sinalizar para o nosso leitor que se trata de duas perguntas distintas, ou melhor, de duas perguntas em uma única. Do montante de entrevistados, 50\% (B2; B4; B6; B7) respondeu apenas à primeira questão, isto é, sobre o que se deve ensinar de inglês hoje; $37,5 \%$ (B1; B3; B5) forneceu resposta completa, ou seja, respondeu à primeira e segunda questões, enquanto que $12,5 \%$ (B8) deu uma resposta que não soubemos categorizar, ao declarar tão somente "acho que não".

Os bolsistas que responderam também à segunda questão, se remeteram ao passado dizendo que se ensinava muito "os conteúdos gramaticais" (B3) e "gramática" (B1). B5 não exemplificou o que se ensinava antigamente, ao registrar a seguinte resposta: "Acredito que não devemos abrir mão das coisas que sempre foram ensinadas sobre a Língua Inglesa, pois se tratam de conhecimentos essenciais e fundamentais para o estabelecimento da língua na cabeça do falante", o que nos faz recordar da concepção bancária de Freire a partir do emprego da partícula "na", pois que o professor deposita conhecimento no falante. Os bolsistas que responderam tão somente à questão primeira ( $O$ que se deve ensinar hoje de inglês?), elencaram os seguintes aspectos: "aspectos culturais" (B1); "contexto" (B2; B7; B3); "letramento crítico" (B2); "direcionar para acúmulo de vocabulário" (B6); "mudar a forma de abordar os conteúdos" (B5); mudar a forma de perceber o inglês "como só mais uma disciplina que está no currículo porque o MEC "prevê" e "obriga" (B4). Destacamos os posicionamentos de $\mathrm{B} 2$ e $\mathrm{B} 4$, pois que o primeiro menciona e valoriza os letramentos críticos enquanto que o último encontra-se refletindo sobre maneiras de contestar a maneira pela qual a língua inglesa é vista. Em nossa leitura, os bolsistas verbalizam um desejo de experimentar coisas novas, problematizar e romper com relações de poder, mas demonstram não saber como promover uma transformação de fato.

Tendo sido interpelados sobre se em termos conceituais, haveria alguma diferença entre os termos práxis e prática, 25\% (B1; B3) não respondeu; 12,5\% (B2) disse estar em dúvida se são semelhantes; 12,5\% (B6) declarou que não sabe contra 50\% (B4; B5; B7; B8) que acredita que significam a mesma coisa. Destacamos que B7, ao complementar sua resposta, arrisca um conceito: "[...] Creio que Práxis e Prática, em conceito, signifiquem prática, realização de trabalhos". Através dos dados gerados, concluímos que é premente que os conceitos devam ser mais bem trabalhados na perspectiva filosófica, que os distingue.

Questionados sobre para que o aluno do Ensino Médio precisa/deva aprender inglês ou se não deve/precisa, 87,5\% dos sujeitos (B2; B3; B4; B5; B6; B7; B8) afirmou que sim, que os alunos devem/precisam aprender inglês no Ensino Médio, contra 12,5\% que declarou que "talvez não precise", isto é, que o ensino de língua inglesa não seja necessário. Quem sinalizou que o ensino de inglês é importante, forneceu as seguintes justificativas: "porque o inglês está presente na vida deles mais do que pensam" (B2); "para se inserirem de modo mais proveitoso nas esferas sociais (trabalho, relações com o outro, lazer) que, hoje em dia, muito se faz o uso da língua" (B3); "para se comunicar com o mundo e entender certos temas que o cercam e irão cercá-lo durante a vida" (B5); "porque é legal" (B4); "para adquirir vocabulário e aprender interpretar textos, que é mais interessante, vendo que vestibulares não são cobrados assuntos de gramática", mas sim um conhecimento mais amplo da língua" (B6); "porque permite que o aluno se insira em um vasto universo de conteúdos e vivências" (B7). Mais uma vez não conseguimos categorizar o posicionamento de B8: "O aluno do ensino médio se ele tiver mesmo interesse em se especializar em inglês ele deve e precisa aprender". 
Por fim, indagados sobre o que têm a dizer sobre o termo formação cidadã, várias foram as versões apresentadas, oriundas, em nossa leitura, de diferentes visões do que a cidadania representa. 50\% (B1; B2; B4; B5) dos bolsistas relacionaram a expressão a vocábulos como "questões sociais", "sociedade"; $25 \%$ (B1; B3) correlacionaram à profissão no que tange as "posturas profissionais e cotidianas". Foram também elencados termos e expressões como "formação da identidade do ser humano" (B5); "ser cidadão do mundo" (B4); tomar "posicionamento de forma autônoma" (B2). Nota-se em B7 uma preocupação com o ser humano em primeira instância, pois que se posiciona assim: "Creio que a formação cidadã refere-se à formação do aluno quanto cidadão e ser humano, não apenas como alguém que aprendeu e reproduziu um conteúdo/ensinamento". Mais uma vez não conseguimos categorizar o que registra B8, uma vez que organiza a sua resposta, na íntegra, da seguinte maneira: "Para mim é um termo que designa boa formação do cidadão".

\section{Da (in)conclusão}

No curso desse artigo, discorremos sobre a modernidade e suas prerrogativas, bem como a necessidade de promoção de sujeitos críticos em face desses novos tempos - o que facilmente nos remete a relevância do campo dos letramentos críticos.

O enquadre teórico construído acerca dos letramentos críticos, bem como dos demais domínios abordados, a saber, práxis e políticas linguísticas, fomentaram as bases para análise dos dados encontrados no questionário de pesquisa, aplicados junto aos alunos bolsistas e membros do PIBID de Língua Inglesa da Universidade Estadual do Sudoeste da Bahia (UESB).

Constatamos que os dados gerados manifestam, qualitativa e quantitativamente, o que podemos seguramente chamar de recorte de docência em Língua Inglesa. Saltam aos nossos olhos (des)estabilizações em curso.

A docência de Língua Inglesa no ensino médio está à deriva, em meio a muitas questões relevantes. Através dos recortes de docência que obtivemos por meio da análise de respostas dos questionários, notamos que ainda circulam algumas concepções preocupantes de língua; receios de repetir os mesmos erros dos demais professores de idioma; adesão à centralidade do papel do professor em sala de aula; questionamentos acerca da representatividade que o livro didático tem em sala de aula; insatisfação em relação à proficiência; parco conhecimento de políticas linguísticas para o ensino de línguas, letramentos críticos, prática e práxis, entre outros temas; preocupação em perder o foco, a linha de pensamento, o controle da aula. Mais importante; o questionário nos revelou uma realidade que pode ser a de muitos outros docentes de línguas: o desconhecimento da finalidade do ensino de Inglês. Podemos, de antemão, apontar que um trabalho de formação continuada seria de grande importância na contínua desestabilização de certezas e na promoção de problematizações, afinal, qual o lugar real da crítica e dos letramentos críticos em sala de aula? Como criar meios de fomentá-los? Quais as implicações dessa empreitada para alunos e professores? Em face não somente da docência de língua inglesa, essas são questões que precisam ser mais bem debatidas e aprofundadas.

\section{Referências}

ANDRE, M. E. D. A. Etnografia da prática escolar. Papirus Editora, 2012.

BAUMAN, Z. Modernidade Líquida. São Paulo: Zahar, 2000. 
BOHN, H. Ensino e aprendizagem de línguas: os atores da sala de aula e a necessidade de rupturas. In: LOPES, L.P da M. Linguística Aplicada na Modernidade Recente: Fetschrift para Antonieta Celani. São Paulo: Parábola, 2013. p. 79-98.

BRASIL. Programa Institucional de Bolsas de Iniciação à Docência (Pibid). Ministério da Educação, 2008. http://portal.mec.gov.br/pibid/pibid. Acesso em 20/01/2016.

BRITISH COUNCIL. Demandas de aprendizagem de Inglês no Brasil: Elaborado com exclusividade para o British Council pelo Instituto de Pesquisa Data Popular. $1^{\text {a }}$ Edição. São Paulo, 2014.

DE SOUSA SANTOS, B. (Org.). Para além do pensamento abissal: das linhas globais a uma ecologia de saberes. In: SANTOS, B. de S; MENESES, M. P. Epistemologias do Sul. São Paulo: Cortez, 2010. p. 31-83.

DUBOC, A. P. M; FERRAZ, D. Letramentos críticos e formação de professores de inglês: currículos e perspectivas em expansão. In: JORDÃO (Org.) Letramentos e Multiletramentos no Ensino de Línguas e Literaturas. Revista X, vol. 1, 2011.

DUBOC, A. P. Atitude curricular: letramentos críticos nas brechas da sala de aula de línguas estrangeiras. Jundiaí, Paco Editorial: 2015.

ELIAS, N. Sobre o Tempo. Rio de Janeiro: Jorge Zahar Editor, 1998.

GREGORY, A. E.; CAHILL, M. A. Constructing critical literacy: Self-reflexive ways for curriculum and pedagogy. In: Critical Literacy: Theories and Practices, v. 3:2, 2009.

JORDÃO, C. M. Abordagem comunicativa, pedagogia crítica e letramentocrítico- farinhas do mesmo saco? In: ROCHA, C. H.; MACIEL, R. F. Língua estrangeira e formação cidadã: por entre discursos e práticas. São Paulo: Pontes, 2013. p. 69-90.

MATTOS, A. M. A.; VALÉRIO, K. M. Letramento crítico e ensino comunicativo: lacunas e interseções. In: RBLA, Belo Horizonte, v. 10, n. 1, p. 135-158, 2010.

MONTE MÓR, W. Crítica e Letramentos Críticos: reflexões preliminares. In: ROCHA, C. H.; FRANCO MACIEL, R. (Orgs.). Língua Estrangeira e Formação Cidadã: por entre discursos e práticas. Coleção: Novas perspectivas em Linguística Aplicada. v. 33, Campinas, SP: Pontes Editores, 2013.

RAJAGOPALAN, K.; SILVA, F. L. L. (Org.). A linguística que nos faz falhar: investigação crítica. São Paulo, SP: Parábola Editorial, 2004.

SANTOS, B. S. Da dogmatização à desdogma-tização da Ciência Moderna. In: SANTOS, B. S. Introdução à Ciência Pós-Moderna. Rio de Janeiro: Graal, p. 2-3, 1989.

SANTOS, M. Técnica, Espaço, Tempo: globalização e meio técnico-científico-informacional. São Paulo: Hucitec, 1994. 
Por uma outra globalização: do pensamento único à consciência universal. 4. ed. Record, Rio de Janeiro, 2000.

TAKAKI, N. H. Contribuições de teorias recentes de letramentos críticos para inglês instrumental. In: RBLA, Belo Horizonte, v. 12, n. 4, p. 971-996, 2012.

VASQUEZ, A. S. Filosofia da Práxis. 2. ed. Rio de Janeiro: Paz e Terra, 1968.

VEIGA-NETO, A. Incluir para excluir. In: LARROSA, J.; SKLIAR, C. (Org.). Habitantes de Babel. Belo Horizonte: Autêntica Editora, 2001. p. 105-118.

WIELEWICKI, V. H. G. Reading foreign literature at university level in Brazil: developing critical readers. In: MENEZES DE SOUZA, L. M. T.; ANDREOTTI, V. Critical Literacy: Theories and Practices. v. 1. Issue 1. CSSGJ, 2007.

Recebido em: maio de 2016.

Aprovado em: agosto de 2016. 